\title{
Growth and Body Composition in PKU Children-A 3 Year Prospective Study Comparing the Effects of L- Amino Acid to Glycomacropeptide Protein Substitutes
}

\section{Anne Daly ( $\sim$ a.daly3@nhs.net)}

Birmingham Women's and Children's NHS Foundation Trust https://orcid.org/0000-0003-2579-8699

\section{Wolfgang Hogler}

Johannes Kepler Universität Linz: Johannes Kepler Universitat Linz

Nicola Crabtree

Birmingham Children's Hospital NHS Foundation Trust: Birmingham Women's and Children's NHS

Foundation Trust

Nick Shaw

Birmingham Children's Hospital NHS Foundation Trust: Birmingham Women's and Children's NHS

Foundation Trust

\section{Sharon Evans}

Birmingham Children's Hospital NHS Foundation Trust: Birmingham Women's and Children's NHS

Foundation Trust

Alex Pinto

Birmingham Children's Hospital NHS Foundation Trust: Birmingham Women's and Children's NHS

Foundation Trust

Richard Jackson

University of Liverpool

\section{Boyd Strauss}

University of Manchester School of Medicine: The University of Manchester Faculty of Biology Medicine and Health

\section{Gisela Wilcox}

Salford Royal Hospitals NHS Trust: Salford Royal NHS Foundation Trust

\section{Julio C Rocha}

Universidade Nova de Lisboa Faculdade de Ciências e Tecnologia: Universidade Nova de Lisboa

Faculdade de Ciencias e Tecnologia

\section{Catherine Ashmore}

Birmingham Children's Hospital NHS Foundation Trust: Birmingham Women's and Children's NHS

Foundation Trust

Anita MacDonald 
Birmingham Children's Hospital NHS Foundation Trust: Birmingham Women's and Children's NHS Foundation Trust

\section{Research}

Keywords: phenylketonuria, body composition, glycomacropeptide, protein substitute

Posted Date: April 5th, 2021

DOI: https://doi.org/10.21203/rs.3.rs-348032/v1

License: (c) (i) This work is licensed under a Creative Commons Attribution 4.0 International License. Read Full License 


\section{Abstract}

Background: Protein quality and quantity are important factors in determining lean body (muscle) mass (LBM). In phenylketonuria (PKU), protein substitutes provide most of the nitrogen either as amino acids (AA) or glycomacropeptide (CGMP-AA). Body composition and growth are important indicators of longterm health. In a 3-year prospective study comparing the impact of AA and CGMP AA on body composition and growth in PKU, 48 children were recruited. $N=19$, (median age 11.1y, range 5-15y) took AA only, $n=16$ (median age 7.3y, range 5-15y) took a combination of CGMP-AA and AA (CGMP50), and 13 children (median age 9.2y, range 5-16y) took CGMP-AA only (CGMP100). A dual energy $X$ ray absorptiometry (DXA) scan at enrolment and 36 months measured LBM, \% body fat (\%BF) and fat mass (FM). Height was measured at enrolment, 12, 24 and 36 months.

Results: No correlation or statistically significant differences were found between the three groups for LBM, FM and height compared with age, gender, puberty or phenylalanine blood concentrations. The change in height $z$ scores: AA 0, CGMP50 +0.4 and CGMP100 +0.7 showed a trend that children in the CGMP100 group were taller, had improved LBM with decreased FM and \% BF but this was not statistically significant.

Conclusion: There appeared to be no advantage of AA compared to CGMP-AA protein substitutes on body composition after 3 years follow up of usage. Although statistical differences were not reached, a trend towards improved body composition was observed with CGMP when it provided the entire protein substitute requirement.

Trial registry: IRAS 129497 (13/WM/10435) registered 10th November 2013 (hppt// www.hra.nhs)

\section{Introduction}

There are concerns about increasing obesity and consequential long-term co-morbidities both in the general and phenylketonuria (PKU) populations [1-3]. A reliance on an 'artificial' diet may alter normal physiological processes such as the distribution of fat and lean mass, adversely affecting long term health outcomes [4]. Body composition is a key component of health, and it typically refers to the quantification of body fat and muscle mass; changes that cannot be adequately assessed by body weight or body mass index (BMI) $[5,6]$. In PKU, reports of body composition are few and there are no long-term prospective studies or systematic/meta analyses reviewing body composition. Therefore, it is difficult to extrapolate any association between body composition and other factors such as muscular fitness, adiposity and longer term health outcomes.

In classical PKU, a low phenylalanine diet requires substantial modification. For most patients with PKU, high biological proteins are excluded (e.g. meat, fish, eggs and dairy products), with low phenylalanine/phenylalanine free protein substitutes providing the principle source of obligatory nitrogen, essential to maintain metabolic control, and enable optimal growth and lean body mass [7, 8]. Muscle contributes $40-45 \%$ of body weight and skeletal muscle is the largest store of peptide and free amino 
acids [9]. Reliance on 'synthetic' nitrogen sources may compromise body composition; lean mass is dependent on amino acid availability and compared to natural protein, delivery and utilization of amino acids from protein substitutes is sub optimal [10-12]

A consistent finding from a systematic and meta-analysis in healthy subjects [13] is that lean mass was found to be a strong predictor of bone mass. Lean mass and therefore bone mass particularly in teenagers with PKU may be compromised as it coincides at a time when adherence with diet and protein substitutes is being challenged $[14,15]$. Additionally, the physiological increase of lean body mass and fat mass differs in adolescent boys and girls, further exacerbating the difficulties in body composition interpretation [16].

The synthetic protein given in PKU is usually derived from amino acids without phenylalanine (AA). More recently, casein glycomacropeptide (CGMP) a bioactive phosphoglycopeptide has been used as an alternative low phenylalanine protein substitute (CGMP-AA). It is associated with better palatability, so adherence is improved [17] but it is unknown if this bioactive macropeptide will alter body composition in PKU. The type of protein, its absorption, and release of amino acids alters insulin and glucagon responses. Insulin stimulates protein synthesis $[18,19]$, while glucagon increases amino acid catabolism. Some non-PKU studies have shown that nitrogen retention is improved when protein is in the form of oligopeptides compared to whole protein or amino acids [20-22]. It is possible that CGMP, a whey derived macropeptide, may promote nitrogen retention improving lean body mass synthesis [23] and improve growth potential in children with PKU.

This 3-year prospective, longitudinal study in children with PKU, aimed to compare the impact of two different sources of protein substitute AA and low phenylalanine CGMP-AA on growth and body composition by comparing height, lean body mass and fat mass.

\section{Materials And Methods \\ 2.1. Methods}

Children were included in the study if they were diagnosed with PKU by newborn screening, aged 5-16 years of age, on dietary treatment only, and adherent with protein substitute with $70 \%$ of routine blood phenylalanine concentrations within phenylalanine target range for 6 months before study enrolment. Target blood phenylalanine ranges for children aged 5-12 years were 120 to $\leq 360 \mu \mathrm{mol} / \mathrm{L}$; and for 13 years and older, 120 to $<600 \mu \mathrm{mol} / \mathrm{L}$ as recommended by the European PKU guidelines [24]

\subsubsection{CGMP-AA and L-amino acid protein substitutes}

Two types of protein substitute were studied: AA or CGMP-AA. AA were either powders made up with water to a semi-solid consistency or ready to drink liquids providing 10,15 or $20 \mathrm{~g}$ of protein equivalent tailored to a child's protein requirements. The CGMP-AA powdered protein substitute (a test product via Vitaflo International Ltd. Liverpool, UK.) contained $36 \mathrm{mg}$ phenylalanine for each $20 \mathrm{~g}$ protein equivalent 
and was reconstituted by adding $120 \mathrm{~mL}$ of water. Both products had a similar energy profile per $20 \mathrm{~g}$ protein equivalent; CGMP-AA, $120 \mathrm{Kcal}, 6.5 \mathrm{~g}$ carbohydrate and $1.5 \mathrm{~g}$ fat; $\mathrm{AA}, 124 \mathrm{Kcal}, 9.4 \mathrm{~g}$ carbohydrate, $0.7 \mathrm{~g}$ fat. Threonine and leucine were higher in the CGMP-AA product.

\subsection{Study Design}

In this prospective longitudinal 3-year study, home visits were conducted 3 monthly collecting dietary assessments, weight, and height. Dual energy $\mathrm{X}$ ray absorptiometry scans (DXA) measured body composition at enrolment and 36 months. At enrolment all the children were on AA protein substitute and had a Tanner pubertal assessment. Following the DXA scan the patients were divided into 3 subgroups.

AA: protein substitute given as AA only

CGMP50: patients tolerating a combination of CGMP-AA and AA

CGMP100: patients tolerating all their protein substitute as CGMP-AA

Due to the negative impact on blood phenylalanine control, only some children were able to meet their protein requirements using only CGMP-AA [25]. Therefore, in addition to the AA group, a third group had to be introduced when CGMP-AA group provided approximately $50 \%$ of protein equivalent intake.

\subsubsection{Selection into L-amino acids or CGMP-AA group.}

The children chose AA or CGMP-AA, depending on their taste preference. Those in the CGMP group entered CGMP50 or CGMP100 groups depending on their phenylalanine blood concentrations.

\subsubsection{Dual $X$ ray absorptiometry (DXA)}

A DXA scan of the total body to assess body composition (fat and lean body mass) was carried out by two trained operators, using a GE Lunar iDXA and Encore TM software version 13.1 (GE Healthcare, Wisconsin MD USA). Trunk thickness and body weight were utilized to ensure that each child was scanned in the most appropriate acquisition mode. Children lay supine on a bed, while the DXA scan was completed. At baseline and 36 months the following parameters were measured: lean body mass (LBM) $\mathrm{g}$, fat mass (FM) g, \% body fat (\%BF), weight $(\mathrm{kg})$, height $(\mathrm{cm})$, and body mass index (BMI) $(\mathrm{kg} / \mathrm{m} 2)$. Daily quality assurance tests were performed according to the manufacturer's instructions. The precision of the instrument was calculated as $1.0 \%$ for fat and $0.5 \%$ for lean in normal weight subjects.

\subsubsection{Anthropometric measurements}

Weight and height were measured by one of two metabolic dietitians. Height was measured using a Harpenden stadiometer (Holtain Ltd, Crymych, UK) and weight on calibrated digital scales (Seca, Medical Measuring Systems and Scales, Birmingham, UK. Model 875); weight was measured to the nearest $0.1 \mathrm{~g}$ and height to the nearest $0.1 \mathrm{~cm}$. Weight, height and BMI were analysed over four time points; baseline, 12,24 and 36 months. 


\subsubsection{Blood phenylalanine levels}

Throughout the study, trained caregivers collected weekly early morning fasted blood spots on filter cards, Perkin Elmer 226 (UK Standard NBS) at home. Blood specimens were sent via first class post to the laboratory at Birmingham Children's Hospital. All the cards had a standard thickness, and the blood phenylalanine concentrations were calculated on a $3.2 \mathrm{~mm}$ punch by MS/MS tandem mass spectrometry.

\subsubsection{Pubertal status}

A general medical examination and pubertal status was measured at enrolment using the Tanner picture index [26]. Stage 1 and 2 were classified as pre-pubertal, and stage 3, 4 and 5 as pubertal.

\subsection{Statistical analysis of anthropometry and body composition}

Continuous data are presented as medians with associated inter-quartile ranges (IQR), categorical data presented as frequencies of counts with associated percentages. Outcome data were divided into anthropometric data, weight $(\mathrm{kg})$, height $(\mathrm{cm})$ and body mass index $(\mathrm{BMI})(\mathrm{kg} / \mathrm{m} 2)$, which were measured as standardised scores and body composition measured as lean body mass $\mathrm{g}, \%$ body fat (\%BF) (kg) and fat mass $\mathrm{g}$. Anthropometric and body composition data were compared with blood phenylalanine concentrations. Standardised height was represented as the change in height and height z-score at each time point relative to baseline. Given the number of patients and the difference in ages between the groups, analysis is performed using longitudinal regression, which adjusts for patient age. Although standardised measures implicitly accounts for patient age, it is retained, as a covariate as in the analysis to avoid any confounding due to age when comparing treatment groups.

Correlations between the outcome data were calculated using Pearson's correlation coefficient. Anthropometric data were analysed using longitudinal modelling techniques including main effects for time and age and evaluating the effect of treatment within each time-point. Models were further adjusted for patient age, accounting for the differences in the enrolment age between the treatment groups. Body composition outcomes were measured at two time points; data was analysed using analysis of covariance (ANCOVA) techniques, analysing the 36 month data as the outcome and adjusting for the enrolment data including patient age at enrolment as well as their pre-pubescent status and gender.

\subsection{Ethical Permission}

The South Birmingham Research Ethics committee granted a favourable ethical opinion referenced 13/WM/0435 and IRAS (integrated research application system) number 129497. Written informed consent was obtained for all subjects from at least one caregiver with parental responsibility and written assent obtained from the subject if appropriate for their age and level of understanding.

\section{Results}




\subsection{Subjects (Table 1)}

Fifty children (28 boys, 22 girls) with PKU were recruited. Forty-seven children were European and 3 of Asian origin. Forty-eight completed the study, 29 in the CGMP-AA group and 19 in the AA group. A significant difference in age was noted between the AA and CGMP50, $(p=0.005)$, and between CGMP50 and CGMP100 $(p=0.04)$.

Table 1

Subject characteristics at recruitment including pubertal status.

\begin{tabular}{|llll|}
\hline & AA & CGMP50 & CGMP100 \\
\hline Number recruited & $n=19$ & $n=16$ & $n=13$ \\
\hline Girls & $n=8$ & $n=8$ & $n=5$ \\
\hline Boys & $n=11$ & $n=8$ & $n=8$ \\
\hline Median age y (range) & $11.1(5-15)$ & $7.3(5-15)$ & $9.2(5-16)$ \\
\hline $\begin{array}{l}\text { \% of children prepubertal } \\
\text { (stage 1 and 2) }\end{array}$ & $32 \%$ & $68 \%$ & $62 \%$ \\
\hline Girls & $n=2$ & $n=6$ & $n=5$ \\
\hline Boys & $n=4$ & $n=5$ & $38 \%$ \\
\hline $\begin{array}{l}\text { \% of children pubertal } \\
\text { (stage 3 to 5) }\end{array}$ & $68 \%$ & $32 \%$ & \\
\hline Girls & $n=6$ & $n=2$ & $n=5$ \\
\hline Boys & $n=7$ & $n=3$ & \\
\hline $\begin{array}{l}\text { AA, amino acid; CGMP, glycomacropeptide; CGMP50 protein substitute based on combination of } \\
\text { CGMP and AA; CGMP100 protein substitute based on CGMP only. }\end{array}$ & \\
\hline
\end{tabular}

\subsection{Pubertal status (Table 1)}

Pre-pubertal status (stage 1 and 2): $32 \%(n=6 / 19)$ were pre-pubertal in the AA group, $68 \%(n=11 / 16)$ in the CGMP50 group and $62 \%(n=8 / 13)$ in the CGMP100 group.

Late puberty (stage 3 to 5): $68 \%(n=13 / 19)$ in the AA group, 32\% $(n=5 / 16)$ in the CGMP50 group and $38 \%(n=5 / 13)$ in the CGMP100 group.

All had classical PKU, except two with mild PKU based on untreated blood phenylalanine levels at diagnosis confirmation following newborn screening, and dietary phenylalanine tolerance. 


\subsection{Subject withdrawal}

One boy and one girl (aged 12 and 11 years respectively) in the CGMP-AA group were excluded from the study, as both were unable to adhere with the study protocol. One failed to return blood phenylalanine samples and both had poor adherence to their phenylalanine restricted diet.

\subsection{Protein substitutes and phenylalanine concentrations}

We have previously reported the type/manufacturers of protein substitutes taken by the AA, CGMP100 and CGMP50 groups. Similarly, the median phenylalanine concentrations have been reported at baseline and year 3 [28]. Median phenylalanine concentrations were within recommended target reference ranges for children aged $\leq 11 \mathrm{y}$ and $\geq 12$ years old [24].

The median daily dose of protein equivalent from protein substitute was $60 \mathrm{~g} / \mathrm{day}$ (range $40-80 \mathrm{~g}$ ), and the median amount of prescribed natural protein was $5.5 \mathrm{~g}$ protein/day (range $3-30 \mathrm{~g}$ ) or $275 \mathrm{mg} /$ day of phenylalanine (range 150-1500mg) in all groups.

\subsection{Body composition lean mass, fat mass and \% body fat (Table 2)}

Body composition was analysed using ANCOVA, adjusting for patient age, gender, phenylalanine concentration and pre-pubescent status. No statistically significant differences were found between the 3 treatment groups for lean body mass, \%BF or fat mass. All parameters increased over the 3-year study period. 
Table 2

Median (range) lean mass, fat mass and \% body fat in the AA, CGMP50and CGMP 100 groups at enrolment and 36 months.

\begin{tabular}{|c|c|c|c|c|}
\hline Body composition & Time of assessment & $\begin{array}{l}\text { AA (range) } \\
n=19\end{array}$ & $\begin{array}{l}\text { GMP50 (range) } \\
n=13\end{array}$ & $\begin{array}{l}\text { GMP100 (range) } \\
\mathrm{n}=16\end{array}$ \\
\hline Lean mass g & Enrolment & $\begin{array}{l}26702 \\
(16920-34209)\end{array}$ & $\begin{array}{l}16334 \\
(14280-17686)\end{array}$ & $\begin{array}{l}20060 \\
(16451-21947)\end{array}$ \\
\hline & $36 \mathrm{~m}$ & $\begin{array}{l}32560 \\
(25893-40511)\end{array}$ & $\begin{array}{l}23921 \\
(22725-26477)\end{array}$ & $\begin{array}{l}31268 \\
(25561-35875)\end{array}$ \\
\hline Delta & & $\begin{array}{l}5858 \\
(6302-8973)\end{array}$ & $\begin{array}{l}7587 \\
(8445-8791)\end{array}$ & $\begin{array}{l}11208 \\
(9110-13928)\end{array}$ \\
\hline Fat mass g & Enrolment & $\begin{array}{l}9528 \\
(6961-15018)\end{array}$ & $\begin{array}{l}5764 \\
(4504-6758)\end{array}$ & $\begin{array}{l}6688 \\
(5057-8811)\end{array}$ \\
\hline & $36 \mathrm{~m}$ & $\begin{array}{l}17216 \\
(10930-20687)\end{array}$ & $\begin{array}{l}12945 \\
(10678-16519)\end{array}$ & $\begin{array}{l}12220 \\
(8347-13101)\end{array}$ \\
\hline Delta & & $\begin{array}{l}7688 \\
(3969-5669)\end{array}$ & $\begin{array}{l}7181 \\
(6174-9761)\end{array}$ & $\begin{array}{l}5532 \\
(3290-4290)\end{array}$ \\
\hline$\%$ body fat $(\mathrm{kg})$ & Enrolment & $\begin{array}{l}29 \\
(23-36)\end{array}$ & $\begin{array}{l}24 \\
(22-28)\end{array}$ & $\begin{array}{l}25 \\
(19-30)\end{array}$ \\
\hline & $36 \mathrm{~m}$ & $\begin{array}{l}35 \\
(25-39)\end{array}$ & $\begin{array}{l}33 \\
(30-36)\end{array}$ & $\begin{array}{l}28 \\
(20-33)\end{array}$ \\
\hline Delta & & 6 & 9 & 3 \\
\hline
\end{tabular}

\subsection{Lean body mass, $\%$ body fat and fat mass}

ANCOVA shows no significant differences in lean body mass, fat mass or \% body fat between the treatment groups. Although a trend for improved lean body mass, fat mass and $\%$ body fat was observed in the CGMP100 group.

\subsection{Changes in height z scores (Table 3, 4 Fig. 1)}


Accounting for the age and gender differences, there were no statistically significant differences for height within or between the groups. At the end of the 3-year study all groups had a positive height $z$ score. We have previously reported weight and BMI z scores over the 36-month period [27] showing no statistical differences between the groups

Statistical modelling showed a trend in the CGMP100 group towards improved growth and a reduction in total body percentage fat and improved lean body mass. Analysis of the delta change in height was divided by age those $\leq 10$ and $\geq 11$ years, this cut off point was taken in line with ESPKU guidelines on differentiation of blood phenylalanine concentrations with age

Table 3

Median Z scores (range) for height in AA, CGMP100 and CGMP50 groups measured annually from enrolment to 36 months in PKU children taking either AA, GMP 50, GMP 100.

\begin{tabular}{|c|c|c|c|}
\hline $\begin{array}{l}\text { Time } \\
\text { (months) }\end{array}$ & $\begin{array}{l}\text { AA } \\
\text { Height } Z \text { score } \\
n=19\end{array}$ & $\begin{array}{l}\text { CGMP50 Height } Z \text { score } \\
n=16\end{array}$ & $\begin{array}{l}\text { CGMP100 Height Z score } \\
n=13\end{array}$ \\
\hline $\begin{array}{l}\text { Enrolment } \\
\text { (range) }\end{array}$ & $0.2(-0.2$ to 0.8$)$ & $-0.1(-0.6$ to 0.6$)$ & $-0.1(-0.4$ to 0.3$)$ \\
\hline $\begin{array}{l}12 \text { months } \\
\text { (range) }\end{array}$ & $0.2(-0.2$ to 0.6$)$ & $0.1(-0.4$ to 0.5$)$ & $0.1(-0.1$ to 0.3$)$ \\
\hline $\begin{array}{l}24 \text { months } \\
\text { (range) }\end{array}$ & $0.2(-0.1$ to 0.5$)$ & $0.2(-0.2$ to 0.5$)$ & 0.4 (0.0 to 0.7$)$ \\
\hline $\begin{array}{l}36 \text { months } \\
\text { (range) }\end{array}$ & 0.2 (0.0 to 0.5$)$ & $0.3(-0.1$ to 0.7$)$ & 0.6 (0.1 to 0.7$)$ \\
\hline DELTA height Z score & 0 & +0.4 & +0.7 \\
\hline
\end{tabular}


Table 4

ANOVA regression model showing values for age, treatment $(A A$, CGMP50, CGMP100) and treatment: time.

\begin{tabular}{|lccccc|}
\hline & Df & Sum Sq & Mean Sq & F value & $\operatorname{Pr}(>\mathrm{F})$ \\
\hline Age & 1 & 0.015 & 0.015 & 0.020 & 0.887 \\
\hline Treatment & 2 & 1.225 & 0.613 & 0.843 & 0.432 \\
\hline Treatment/ time & 3 & 2.081 & 0.694 & 0.954 & 0.415 \\
\hline Residuals & 185 & 134.418 & 0.727 & & \\
\hline 1 = AA, 2 = CGMP50, 3 = CGMP100. & & & \\
\hline
\end{tabular}

\section{Discussion}

Body composition and height over 36 months in a group of children taking CGMP or AA protein substitutes showed no statistically significant changes in any of the measured parameters. However, in the CGMP100 group, statistical modelling indicated a trend ( $p$ 0.42) towards improved longitudinal growth, a reduction in fat mass, \% body fat and improved lean body mass. When growth is represented as a median change from baseline over time, it shows the CGMP100 group had the greatest change in height. However, age modifies this trend and although the CGMP100 group continues to show an improved height growth it does not reach significance.

We can only speculate about a suggested trend in improved body composition when taking CGMP as the complete source of protein substitute. One possible explanation is the bioactivity of CGMP; it is rich in the branched chain amino acids isoleucine and leucine, which are potent modulators of protein turnover and have been shown to have a significant effect on insulin and glucose metabolism [28, 29]. If CGMP by the action of these amino acids improved insulin sensitivity it is possible growth may be improved. However, we did not collect any information on insulin resistance in this group of subjects, so it is difficult to draw any firm conclusions.

Huemer et al [30] measured growth and body composition over 12 months in 34 children with classical PKU. Total protein intake was $124 \%$ of the German recommended daily allowance. A significant correlation was found between lean body mass and intake of natural protein suggesting that improved natural protein intake was beneficial. Evans et al [31] also reported a similar significant relationship between a lower \% fat mass and a higher total, natural and protein substitute intake, with natural protein $>0.5 \mathrm{~g} / \mathrm{kg} /$ day associated with an improved body composition, no relationship was found between natural protein intake and improved height $z$ scores. Evans, similar to Hoeksman et al [32] observed that neither natural protein or energy intake correlated with linear growth as reported by Aldamiz Echevarria et al. [33]. The effect of a low protein diet on energy balance and postprandial fat oxidation has received little attention in PKU subjects. A study by Alfheeaid et al [34] reported a lower thermal effect of feeding and fat oxidation after healthy subjects had taken a meal containing special low protein foods and 
protein substitutes, possibly leading to a higher fat mass and altered body composition. Patients with milder PKU, responsive to sapropterin dihydrochloride $(\mathrm{BH} 4)$, have a higher natural protein tolerance but there appears to be no advantage in height, weight, body mass index or growth velocity, when $\mathrm{BH} 4$ was compared to conventional PKU therapy [35]. There are no studies reporting body composition in $\mathrm{BH} 4$ responsive patients who use less low protein food products and have a wider range of natural protein sources compared to the classically treated patients with PKU.

The importance of an adequate protein intake from protein substitutes (both quality and quantity) in PKU has been documented by many authors [36-41]. No studies have identified the protein digestibility score or absorption kinetics of CGMP protein substitutes; this is important to ascertain protein efficiency. In healthy adults protein containing meals taken at regular intervals improve skeletal muscle protein by $25 \%$, reinforcing the need to consume protein substitutes in divided doses [42-44]. The optimal amount of protein substitute based on free amino acids or CGMP remains undefined, but any factor leading to protein inefficiency may compromise body composition, optimal height and increase the incidence of overweight. Other confounding factors that may affect body composition is the effect of a long term low phenylalanine diet higher in carbohydrate which may be associated with a higher risk of adiposity and insulin resistance $[45,46]$. All these factors may lead to underachievement of an optimal growth potential in PKU children [47].

Comparison of body composition by gender regardless of group showed lean body mass was statistically significantly higher in males than females consistent with reports in the literature $(p=0.013)$ [48]. Fat mass and lean body mass vary with age, gender and pubertal status. Various authors have reported an age related increase in lean body mass index being more rapid in males compared with females particularly between the ages of 11-16y, in line with rapid accrual of lean body mass during male puberty [49]. Children gain lean mass disproportionately to height and this is more pronounced in boys compared to girls [48].

A multitude of methods exist for assessing body composition, including DXA, bioelectrical impedance (BIA), and whole body air displacement plethysmograph (Bodpod), each having their own assumptions, advantages and inadequacies [50]. Unfortunately, there is a lack of standardised reference data, making interpretation and comparison of results challenging. Sensitive and accurate measurements are needed to detect differences in visceral compared to central fat accumulation, as ponderal and body mass index alone are unable to detect subtle differences. The gold standard for measuring body composition is a four-compartment (4C) model [51]. DXA has been evaluated against $4 \mathrm{C}$ models in children, and although it overestimates body fat by $1-4 \%$ depending on age, sex and body size, the correlation compared to a $4 \mathrm{C}$ model is good despite the small error [52,53]. Reference data for comparison of body composition parameters is limited; a recent publication Ofenheimer [54] has produced age and gender specific reference percentiles of body composition parameters for European children and adolescents. Comparison of our data would indicate appropriate body composition for fat and lean body mass when calculated as a median between baseline to 36 months. 
There are limitations to this study, we do not have a healthy reference control group or UK based reference date to compare body composition parameters, an inherent problem using the DXA for body composition analysis. Endocrine parameters such as bone age or growth hormone were not measured which may have explained differences in linear growth. Until kinetic studies are conducted, it is unknown if a peptide compared to amino acids alters the delivery and assimilation of amino acids leading to improved lean body mass and growth. We did not collect parental height data, which may have been useful as a comparison within the groups. Not all the children were able to replace their full requirement of amino acids with CGMP AA completely, which may have reduced the strength of our findings. There were small numbers of children in each study group, the older children chose to stay on their AA supplement compared to the younger age group who were more agreeable to try an alternative protein substitute, which may have led to some bias.

\section{Conclusion}

In this 3-year longitudinal study we found no noticeable differences in body composition between the group taking CGMP AA and AA. However, there was a trend towards improved body composition in the group taking all their protein substitute as CGMP-AA. This may suggest CGMP does confer some biological benefit. Proof of concept will only come via larger controlled studies and over longer duration throughout childhood years.

\section{Declarations}

Ethics approval: has been given and cited in the main text.

Consent for publication: there are not materials that would contravene consent for publication

Trial registry: IRAS 129497 (13/WM/10435)10th November 2013 hppt// www.hra.nhs

Availability of data and materials all the manuscript data generated and analysed during this study are available from the corresponding author on reasonable request

Funding: AD research funding from Vitaflo International, financial support from

Availability of data and materials: Please contact the author for data requests

Competing interests: Nutricia, Mevalia \& Vitaflo International to attend study days \& conferences. SE. research funding from Nutricia, financial support from Nutricia \& Vitaflo International to attend study days \& conferences AP has received an educational grant from Cambrooke Therapeutics and grants from Vitaflo International, Nutricia, Merck Serono, Biomarin and Mevalia to attend scientific meetings. CA received honoraria from Nutricia and Vitaflo International to attend study days and conferences. JCR member of the European Nutritionist Expert Panel (Biomarin), the Advisory Board for Applied Pharma Research and Nutricia, and received honoraria as a speaker from APR, Merck Serono, Biomarin, Nutricia, 
Vitaflo, Cambrooke, PIAM and Lifediet. AMD research funding \& honoraria from Nutricia, Vitaflo International \& Merck Serono, Member of European Nutrition Expert Panel (Merck Serono international), member of Sapropterin Advisory Board (Merck Serono international), member of the Advisory Board Element (Danone-Nutricia);The funders had no role in the design of the study; in the collection, analyses, or interpretation of data; in the writing of the manuscript, or in the decision to publish the results.

Author Contributions: Conceptualization, AMD, AD; methodology, AMD, AD; software, RJ, AD; validation, $A M D, A D, S E, A P, C A$; JCR formal analysis, $A D$, RJ; investigation, $A D, A M D$; writing-original draft preparation, AD,AMD.; writing-review and editing, AD, SE, AP, RJ, JCR, AMD; supervision, AMD.

\section{References}

1. Abdullah, A., et al., The magnitude of association between overweight and obesity and the risk of diabetes: a meta-analysis of prospective cohort studies. Diabetes Res Clin Pract, 2010. 89(3): p. 30919.

2. Moreno, L.A., et al., Leptin and metabolic syndrome in obese and non-obese children. Horm Metab Res, 2002. 34(7): p. 394-9.

3. Sarria, A., et al., Body mass index, triceps skinfold and waist circumference in screening for adiposity in male children and adolescents. Acta Paediatr, 2001. 90(4): p. 387-92.

4. Kelly, D.A., Nutritional factors affecting growth before and after liver transplantation. Pediatr Transplant, 1997. 1(1): p. 80-4.

5. Cole, T.J., J.V. Freeman, and M.A. Preece, Body mass index reference curves for the UK, 1990. Arch Dis Child, 1995. 73(1): p. 25-9.

6. Javed, A., et al., Diagnostic performance of body mass index to identify obesity as defined by body adiposity in children and adolescents: a systematic review and meta-analysis. Pediatr Obes, 2015. 10(3): p. 234-44.

7. Dokoupil, K., et al., Optimising growth in phenylketonuria: current state of the clinical evidence base. Clin Nutr, 2012. 31(1): p. 16-21.

8. MacDonald, A., et al., Protein substitute dosage in PKU: how much do young patients need? Arch Dis Child, 2006. 91(7): p. 588-93.

9. Wu, G., Dietary protein intake and human health. Food Funct, 2016. 7(3): p. 1251-65.

10. Gropper, S.S. and P.B. Acosta, Effect of simultaneous ingestion of L-amino acids and whole protein on plasma amino acid and urea nitrogen concentrations in humans. JPEN J Parenter Enteral Nutr, 1991. 15(1): p. 48-53.

11. Gropper, S.S., D.M. Gropper, and P.B. Acosta, Plasma amino acid response to ingestion of L-amino acids and whole protein. J Pediatr Gastroenterol Nutr, 1993. 16(2): p. 143-50.

12. Monch, E., et al., Utilisation of amino acid mixtures in adolescents with phenylketonuria. Eur $\mathrm{J}$ Pediatr, 1996. 155 Suppl 1: p. S115-20. 
13. Smith, J.J., et al., The health benefits of muscular fitness for children and adolescents: a systematic review and meta-analysis. Sports Med, 2014. 44(9): p. 1209-23.

14. MacDonald, A., et al., Adherence issues in inherited metabolic disorders treated by low natural protein diets. Ann Nutr Metab, 2012. 61(4): p. 289-95.

15. Walter, J.H., et al., How practical are recommendations for dietary control in phenylketonuria? Lancet, 2002. 360(9326): p. 55-7.

16. Kleinman.RE and F.R. Greer, Pediatric Nutrition. 2019: American Academy of Pediatrics. 1731.

17. Lim, K., et al., Acceptable low-phenylalanine foods and beverages can be made with glycomacropeptide from cheese whey for individuals with PKU. Mol Genet Metab, 2007. 92(1-2): p. 176-8.

18. Boucher, J., et al., Differential Roles of Insulin and IGF-1 Receptors in Adipose Tissue Development and Function. Diabetes, 2016. 65(8): p. 2201-13.

19. James, H.A., B.T. O'Neill, and K.S. Nair, Insulin Regulation of Proteostasis and Clinical Implications. Cell Metab, 2017. 26(2): p. 310-323.

20. Adibi, S.A., Intestinal transport of dipeptides in man: relative importance of hydrolysis and intact absorption. J Clin Invest, 1971. 50(11): p. 2266-75.

21. Akhavan, T., et al., Effect of premeal consumption of whey protein and its hydrolysate on food intake and postmeal glycemia and insulin responses in young adults. Am J Clin Nutr, 2010. 91(4): p. 96675 .

22. Silk, D.B., et al., Use of a peptide rather than free amino acid nitrogen source in chemically defined "elemental" diets. JPEN J Parenter Enteral Nutr, 1980. 4(6): p. 548-53.

23. van Calcar, S.C., et al., Improved nutritional management of phenylketonuria by using a diet containing glycomacropeptide compared with amino acids. Am J Clin Nutr, 2009. 89(4): p. 1068-77.

24. van Wegberg, A.M.J., et al., The complete European guidelines on phenylketonuria: diagnosis and treatment. Orphanet J Rare Dis, 2017. 12(1): p. 162.

25. Daly A, et al., Glycomacropeptide in children with PKU: does its phenylalalnine content affect blood phenylalanine control? Journal of Human Nutrition and Dietetics, 2017. On line 22nd Jan 2017.

26. Tanner, J.M. and R.H. Whitehouse, Clinical longitudinal standards for height, weight, height velocity, weight velocity, and stages of puberty. Arch Dis Child, 1976. 51(3): p. 170-9.

27. Daly, A., et al., The Impact of the Use of Glycomacropeptide on Satiety and Dietary Intake in Phenylketonuria. Nutrients, 2020. 12(9).

28. Bifari, F. and E. Nisoli, Branched-chain amino acids differently modulate catabolic and anabolic states in mammals: a pharmacological point of view. Br J Pharmacol, 2017. 174(11): p. 1366-1377.

29. Lynch, C.J. and S.H. Adams, Branched-chain amino acids in metabolic signalling and insulin resistance. Nat Rev Endocrinol, 2014. 10(12): p. 723-36.

30. Huemer, M., et al., Growth and body composition in children with classical phenylketonuria: results in 34 patients and review of the literature. J Inherit Metab Dis, 2007. 30(5): p. 694-9. 
31. Evans, M., H. Truby, and A. Boneh, The relationship between dietary intake, growth and body composition in Phenylketonuria. Mol Genet Metab, 2017. 122(1-2): p. 36-42.

32. Hoeksma, M., et al., The intake of total protein, natural protein and protein substitute and growth of height and head circumference in Dutch infants with phenylketonuria. J Inherit Metab Dis, 2005. 28(6): p. 845-54.

33. Aldamiz-Echevarria, L., et al., Anthropometric characteristics and nutrition in a cohort of PAH-deficient patients. Clin Nutr, 2014. 33(4): p. 702-17.

34. Alfheeaid, H., et al., Impact of phenylketonuria type meal on appetite, thermic effect of feeding and postprandial fat oxidation. Clin Nutr, 2018. 37(3): p. 851-857.

35. Aldamiz-Echevarria, L., et al., Tetrahydrobiopterin therapy vs phenylalanine-restricted diet: impact on growth in PKU. Mol Genet Metab, 2013. 109(4): p. 331-8.

36. Acosta, P.B. and S. Yannicelli, Protein intake affects phenylalanine requirements and growth of infants with phenylketonuria. Acta Paediatr Suppl, 1994. 407: p. 66-7.

37. Acosta, P.B., et al., Nutrient intakes and physical growth of children with phenylketonuria undergoing nutrition therapy. J Am Diet Assoc, 2003. 103(9): p. 1167-73.

38. MacDonald, A., et al., Administration of protein substitute and quality of control in phenylketonuria: a randomized study. J Inherit Metab Dis, 2003. 26(4): p. 319-26.

39. Rocha, J.C., et al., Weight Management in Phenylketonuria: What Should Be Monitored. Ann Nutr Metab, 2016. 68(1): p. 60-5.

40. Weglage, J., et al., Growth in patients with phenylketonuria. Eur J Pediatr, 1994. 153(7): p. 537-8.

41. Rocha, J.C. and A. MacDonald, Dietary intervention in the management of phenylketonuria: current perspectives. Pediatric Health Med Ther, 2016. 7: p. 155-163.

42. Herrmann, M.E., et al., Dependence of the utilization of a phenylalanine-free amino acid mixture on different amounts of single dose ingested. A case report. Eur J Pediatr, 1994. 153(7): p. 501-3.

43. MacDonald, A., et al., Factors affecting the variation in plasma phenylalanine in patients with phenylketonuria on diet. Arch Dis Child, 1996. 74(5): p. 412-7.

44. MacDonald, A., et al., Does a single plasma phenylalanine predict quality of control in phenylketonuria? Arch Dis Child, 1998. 78(2): p. 122-6.

45. Couce, M.L., et al., New insights in growth of phenylketonuric patients. Eur J Pediatr, 2015. 174(5): p. 651-9.

46. Moretti, F., et al., Dietary glycemic index, glycemic load and metabolic profile in children with phenylketonuria. Nutr Metab Cardiovasc Dis, 2017. 27(2): p. 176-182.

47. Ilgaz, F., et al., Long-Term Growth in Phenylketonuria: A Systematic Review and Meta-Analysis. Nutrients, 2019. 11(9).

48. Wells, J.C., et al., Body-composition reference data for simple and reference techniques and a 4component model: a new UK reference child. Am J Clin Nutr, 2012. 96(6): p. 1316-26. 
49. Weber, D.R., et al., Fat and lean BMI reference curves in children and adolescents and their utility in identifying excess adiposity compared with BMI and percentage body fat. Am J Clin Nutr, 2013. 98(1): p. 49-56.

50. Wells, J.C., et al., Body composition in normal weight, overweight and obese children: matched casecontrol analyses of total and regional tissue masses, and body composition trends in relation to relative weight. Int J Obes (Lond), 2006. 30(10): p. 1506-13.

51. Roemmich, J.N., et al., Alterations in growth and body composition during puberty. I. Comparing multicompartment body composition models. J Appl Physiol (1985), 1997. 83(3): p. 927-35.

52. Sopher, A.B., et al., Measurement of percentage of body fat in 411 children and adolescents: a comparison of dual-energy X-ray absorptiometry with a four-compartment model. Pediatrics, 2004. 113(5): p. 1285-90.

53. Williams, J.E., et al., Evaluation of Lunar Prodigy dual-energy X-ray absorptiometry for assessing body composition in healthy persons and patients by comparison with the criterion 4-component model. Am J Clin Nutr, 2006. 83(5): p. 1047-54.

54. Ofenheimer, A., et al., Reference charts for body composition parameters by dual-energy X-ray absorptiometry in European children and adolescents aged 6 to 18 years-Results from the Austrian LEAD (Lung, hEart, sociAl, boDy) cohort. Pediatr Obes, 2021. 16(1): p. e12695.

\section{Figures}

Subjects $<=10$ years old

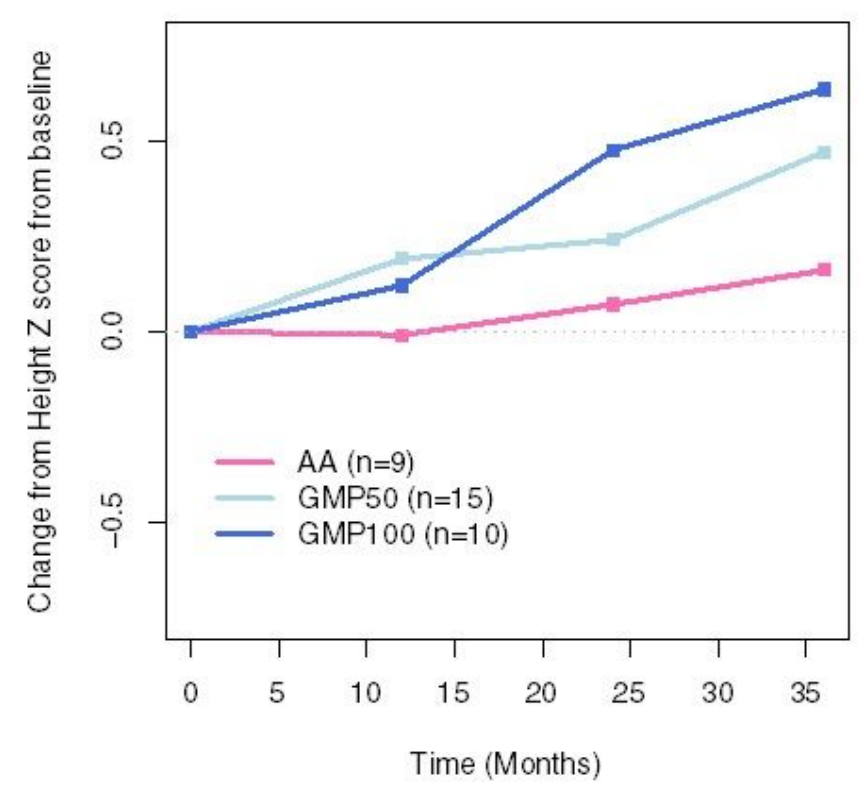

Subjects $>=11$ years old

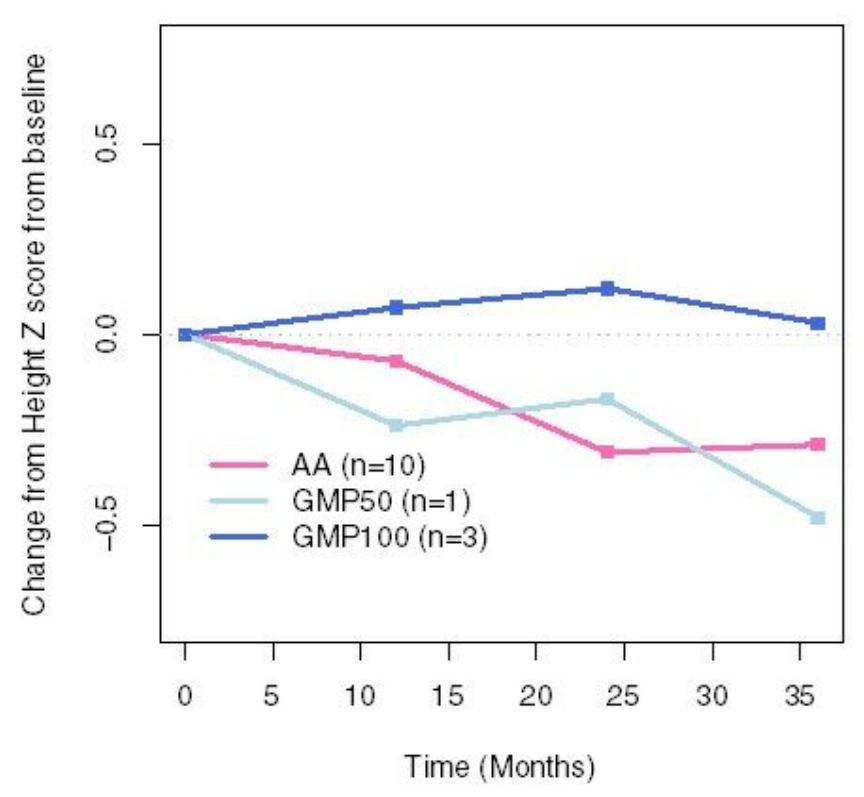

\section{Figure 1}

Change in median height z-score from baseline to 36 months in the AA, GCMP100 and CGMP 50 groups. 